\title{
Volume and Mass Measurement of a Burning Wood Pellet by Image Processing
}

\author{
Sae Byul Kang ${ }^{1, *}$, Bong Suk Sim ${ }^{2}$ and Jong Jin Kim ${ }^{1}$ \\ 1 Energy Network Laboratory, Korea Institute of Energy Research, Daejeon 34129, Korea; jjkim@kier.re.kr \\ 2 Research and Development Team, Doowon, Choongnam 336864, Korea; bssim@dwdcc.co.kr \\ * Correspondence: byulkang@kier.re.kr; Tel.: +82-42-860-3321
}

Academic Editors: Mejdi Jeguirim and Lionel Limousy

Received: 2 March 2017; Accepted: 12 April 2017; Published: 1 May 2017

\begin{abstract}
Wood pellets are a form of solid biomass energy and a renewable energy source. In 2015, the new and renewable energy (NRE) portion of wood pellets was $4.6 \%$ of the total primary energy in Korea. Wood pellets account for $6.2 \%$ of renewable energy consumption in Korea, the equivalent of $824,000 \mathrm{TOE}$ (ton of oil equivalent, 10 million kcal). The burning phases of a wood pellet can be classified into three modes: (1) gasification; (2) flame burning and (3) charcoal burning. At each wood pellet burning mode, the volume and weight of the burning wood pellet can drastically change; these parameters are important to understand the wood pellet burning mechanism. We developed a new method for measuring the volume of a burning wood pellet that involves no contact. To measure the volume of a wood pellet, we take pictures of the wood pellet in each burning mode. The volume of a burning wood pellet can then be calculated by image processing. The difference between the calculation method using image processing and the direct measurement of a burning wood pellet in gasification mode is less than $8.8 \%$. In gasification mode in this research, mass reduction of the wood pellet is $37 \%$ and volume reduction of the wood pellet is $7 \%$. Whereas in charcoal burning mode, mass reduction of the wood pellet is $10 \%$ and volume reduction of the wood pellet is $41 \%$. By measuring volume using image processing, continuous and non-interruptive volume measurements for various solid fuels are possible and can provide more detailed information for CFD (computational fluid dynamics) analysis.
\end{abstract}

Keywords: combustion; image processing; renewable; volume measurement; wood pellet

\section{Introduction}

With increased fossil fuel prices, the heating costs of households and industry have increased rapidly. Many countries are interested in using renewable energy to decrease consumption of fossil fuel. Wood pellet is a kind of solid biomass energy and a renewable energy source. In 2015, the new and renewable energy portion of wood pellets was $4.6 \%$ with respect to the total primary energy in Korea. Most of the renewable energy in Korea is from waste energy, reaching $63.5 \%$. The other renewable energy sources have much smaller contributions, with the bioenergy portion being $20.8 \%$, wind energy $2.1 \%$, solar power $6.4 \%$ and solar heat $0.2 \%$ [1]. In 2016, the total amount of wood pellet produced in Korea was 52.7 thousand tons and the imported wood pellet amount was 1.72 million tons which was mainly used in power plants for co-firing with coal [2]. Most of Korea's imported wood pellet is from Vietnam, Malaysia and Indonesia. The amount of imported wood pellet into Korea was about $8.5 \%$ of the amount of wood pellet consumed in the EU in 2015 (20.3 million tons) [3].

European countries such as Germany, Austria, and Sweden have developed wood pellet boilers and have common norms around the solid biomass boiler, EN 303-5:2012, which classifies and describes the requirements and testing methods of the solid biomass boiler [4]. Fiedler reviewed the state of the art of, small scale pellet-based heating system and relevant regulation in Sweden, Austria and 
Germany. He categorized pellet central heating boilers and burners [5]. Recently, lots of studies related to pellet burning use mixed pellet with other solid fuel, such as coal [6], agricultural residue $[7,8]$, bamboo [9,10] and potato pulp [11].

Wood combustion is a complex process that involves many physical and chemical processes. Burning phases of wood pellets can be classified into three modes: (1) gasification; (2) flame burning; and (3) charcoal burning. At each wood pellet burning mode, the volume and weight of the burning wood pellets can drastically change and these parameters are therefore important in understanding the wood pellet burning mechanism. Volume change and burning time at each mode of wood pellet can be important data in designing the combustor of the wood pellet boiler, especially the combustor with the moving stoker type. The main design parameters of moving stoker type wood pellet combustor are (1) shape of grate; (2) number of grate; (3) velocity and moving interval of grate; (4) and combustion air distribution. Volume change and duration of each combustion mode of wood pellet can be useful in determining those design parameters.

Thunman et al. presented a particle model of combustion of wood particles for Eulerian calculations. They performed calculations and compared the results with experimental results for more than 60 samples of particles of different sizes. The model they developed shows the strong influence of shrinkage on devolatilization and char combustion times [12]. Park et al. [13] performed an experimental and theoretical investigation of heat and mass transfer processes during wood pyrolysis. They performed pressure calculations based on a new pyrolysis model and revealed that high pressure is generated inside the biomass particles during pyrolysis. Moreover, sample splitting was observed during the experiments. The splitting is due to both weakening of the structure and the internal pressure generation that takes place during pyrolysis. At low heating rates, structural weakness is the primary factor, whereas at high heating rates, internal pressure is the determining factor [14]. Hshieh and Richards reported the effects of preheating wood on the ignition temperature of wood char. They found that the preheated samples were further heated in air at $5{ }^{\circ} \mathrm{C} / \mathrm{min}$ to unpiloted ignition. Despite major chemical changes during the various preheating treatments, the ignition temperatures were not significantly affected, except for a slight decrease $\left(11^{\circ} \mathrm{C}\right)$ after five days at $150^{\circ} \mathrm{C}$ in air [14]. Ward and Braslaw reported experimental weight loss kinetics of wood pyrolysis under a vacuum. The results showed that kinetic parameters can be used to predict the volatilization rates of wood as a function of temperature in a vacuum. The model can also be used to estimate the quantities of each of the main components initially present in an unknown wood sample [15]. Lautenberger and Fernandez-Pello studied a model for the oxidative pyrolysis of wood. They performed optimized model calculations for mass loss rate, surface temperature, and depth temperatures and reproduced the experimental data well, including the experimentally observed increase in temperature and mass loss rate with increasing oxygen concentration [16]. Kung and Kalelkar determined the heat of the pyrolysis reaction with a mathematical model [17]. Biswas et al. studied on effect of pelletizing conditions on combustion behavior of single wood pellet. They measured a single burning pellet weight by a precision scale during combustion test. They found that time for a single pellet combustion increased with pelletizing temperature and time for flame combustion was about $50 \mathrm{~s}$; time for char oxidation was about $100 \mathrm{~s} \mathrm{[18].} \mathrm{Fagerström} \mathrm{et} \mathrm{al.} \mathrm{also} \mathrm{measured} \mathrm{the} \mathrm{weight} \mathrm{of} \mathrm{the} \mathrm{wood} \mathrm{pellet} \mathrm{during}$ the combustion test using a precision scale to determine the release of ash forming elements after the devolatilization phase and the char combustion [19]. Ström and Thunman developed a numerical model for drying and devolatilization of moist wood particles in an inert condition [20]. The results from the CFD calculation were compared with previous experimental data and both were in alignment. Sengupta et al. measured yarn parameters by an image processing technique with a low cost web camera. They measured diameter, diameter variation, and number of thick/thin places [21]. Taghavifar and Mardani measured the contact area of a radial ply tire with the image processing method [22]. They captured RGB data of tire contact area image then converted it to hue, saturation and value (HSV) data to calculate tire contact area. 
Arce et al. [23] investigated wood pellet combustion characteristics on a fixed bed reactor (FBR) with various conditions. They concluded that the particle size of the wood pellet and water content are major parameters on combustion and heat transfer. Moradian et al. [24] performed the combustion test on a fluidized bed boiler with fuel of a normal solid waste and compared it to mixing with animal wastes. They found that solid waste comprised of $20-30 \%$ animal waste reduced the bed temperature by $70-100{ }^{\circ} \mathrm{C}$ and suppressed the deposition growth rate. Chun et al. [25] investigated pyrolysis and gasification characteristics of sewage sludge with a high water and nitrogen content. Their study focused on high quality gas and char production.

Gomez et al. [26] did a simulation study on the effect of water temperature on domestic biomass boiler performance. Their results concluded that low water temperature increased heating performance but also increased $\mathrm{CO}$ emission.

The main purpose of the present study was to measure the density and volume of a wood pellet without disturbing combustion condition. Previous studies use a precise electric scale to measure the weight of the burning wood pellet $[13,15,18,19]$. In this study, we calculate the volume of the burning wood pellet based on the image processing method and we also determine the mass of the burning wood pellet with measured density of the bare wood pellet and the charcoal of the wood pellet. We took combustion state photographs for each mode by recoding video. In order to investigate the volume reduction rate of a wood pellet in combustion, moving images of wood pellet combustion were captured. From the captured moving images, we calculated the volume of the wood pellet at each time point. This research will provide useful background for applying combustor design, analysis, and operation to wood pellet boilers.

\section{Method}

In an image file format, such as JPG, $N \times M \times 3$ matrix data are used to construct an image. Each $N \times M$ matrix has the information of the red, green and blue (RGB) data of the image, the three elements of color. In the matrix, the first $N \times M$ matrix has $x$ and $y$ coordinate data. In the image file, the RGB data can have values from 0 to 255 , which is based on 8 bit data.

With the RGB data from an image file, we developed a volume calculation method for an axisymmetric object. If the diameter of the finite volume of an axisymmetric object is known, the volume can be calculated by integration of the finite volume. The radius of an axisymmetric object can be obtained by image processing. With image data, if the border of the axisymmetric object is found, the radius and finite height of a small volume of the axisymmetric object can be obtained. With the obtained border data of the axisymmetric object from the image file, the volume of the axisymmetric object can be calculated.

Figure 1 shows a sample image file of a wood pellet and the lines represent the following: $x=9$, 150 and 252 pixel. Along the line in the picture, RGB data can be plotted as shown in Figure 2. On the $x=9$ line in the image data, there is no wood pellet image but only background. Therefore, the RGB data along the line at $x=9$ should not be changed abruptly. In contrast, on the $x=150$ line in the image data, both the background and the wood pellet are present. Therefore, if RGB data along the line at $x=150$ are plotted, there must be two abrupt changes at each border of the wood pellet (Figure 3). On the line at $x=252$ in the image file, both the background and a thin pin supporting the wood pellet are present. Again, there must be two abrupt changes on the RGB line along the $x=252$ line (Figure 4). However, the distance between the two changes is shorter than the distance of the $x=150$ line.

Figure 5 shows a wood pellet in flame burning mode. There is a flame in the middle of the wood pellet. Figure 6 represents RGB data along $x=150$ of wood pellet of Figure 5. Compared to the RGB data in Figure 3 of the wood pellet in gasification mode, the absolute values of RGB data of the wood pellet in flame burning mode differ from each other, such as at $y=20 R$ value is about $200, G$ value is about 140 and $B$ value is about 100 . However, there are also two abrupt changes of RGB data at the $x=150$ line, as seen in Figure 6. Thus, we can obtain a border line of the wood pellet in flame burning mode. 
If the boundary of the wood pellet is obtained, the volume of the pellet (an axisymmetric object) can be assumed to be an infinitesimal cylinder. However, if the axis of symmetry is not parallel with respect to the $x$-axis, the volume calculation will have error due to an incorrect estimation of the diameter. It is very difficult to align a wood pellet with a vertical line. In Figure 1, the wood pellet is tilted 8.2 degrees from a vertical line. In the error calculation, the diameter and height of the wood pellet are $6 \mathrm{~mm}$ and $22 \mathrm{~mm}$, respectively. If the misalignment angle is less than 10 degrees, the maximum volume calculation error will be less than $0.5 \%$. In the volume calculation, coordinate transformation is used as follows:

$$
\left[\begin{array}{l}
x^{\prime} \\
y^{\prime}
\end{array}\right]=\left[\begin{array}{c}
\cos (\theta)-\sin (\theta) \\
\sin (\theta) \cos (\theta)
\end{array}\right]\left[\begin{array}{l}
x \\
y
\end{array}\right]
$$

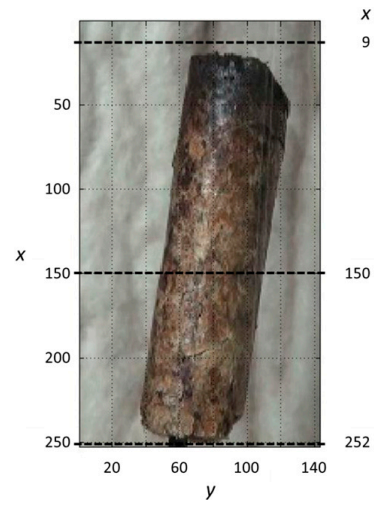

Figure 1. Image file of a wood pellet in gasification mode and lines of $x=9,150$ and 252.

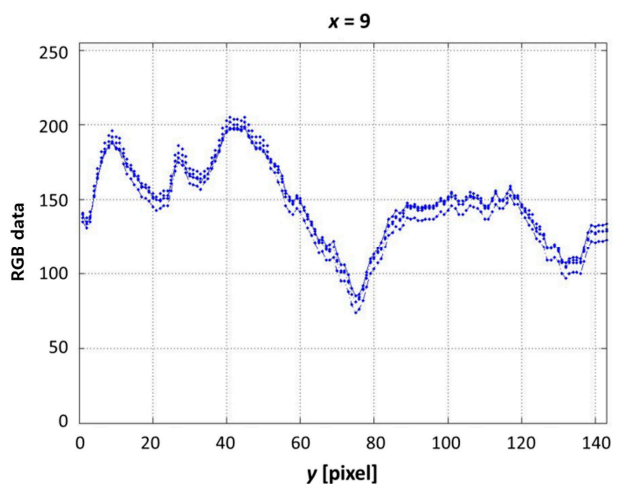

Figure 2. Red, Green and Blue (RGB) data of image file of wood pellet (Figure 1) along $y$ pixel at $x=9$.

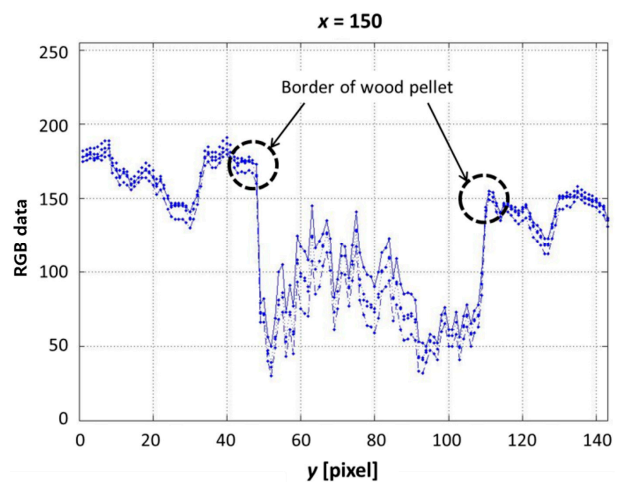

Figure 3. RGB data of image file of wood pellet (Figure 1) along $y$ pixel at $x=150$. 


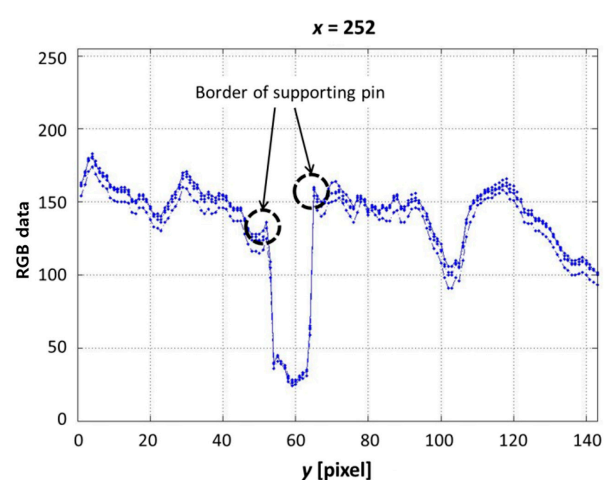

Figure 4. RGB data of image file of wood pellet (Figure 1) along $y$ pixel at $x=252$.

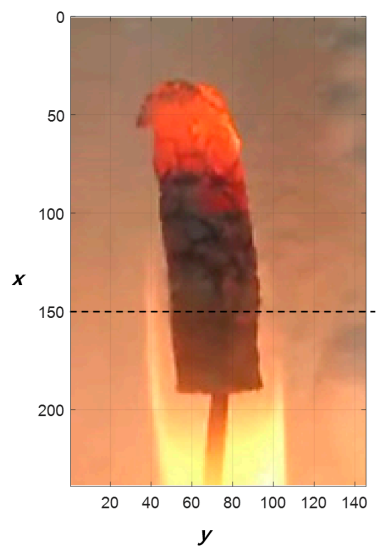

Figure 5. Image file of a wood pellet in flame burning mode and line of $x=150$.

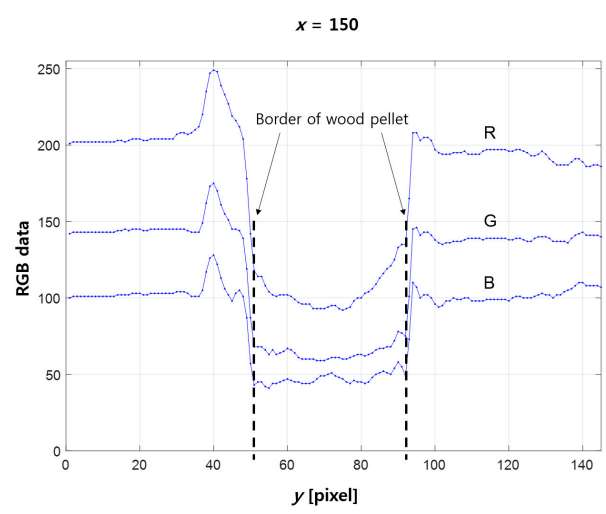

Figure 6. RGB data of image file of wood pellet in flame burning mode (Figure 5) along y pixel at $x=150$.

Figure 7 shows (a) a raw image file of a wood pellet; (b) the border line of the wood pellet and (c) the border line of the wood pellet with rotation. As seen in this figure, the border line of the pellet is precisely found.

To confirm the accuracy of this volume calculation method, we compare the volume of an "AAA" type battery that is manually measured by vernier caliper with one that is measured by the image processing method.

Figure 8 shows a picture of the battery and the captured boundary result by the image processing program. The diameter and length of the "AAA" type battery are $10.27 \mathrm{~mm}$ and $42.39 \mathrm{~mm}$, respectively. If the battery is assumed to be asymmetrical, the volume of the battery is $3511.51 \mathrm{~mm}^{3}$. By the image 
processing method, the volume of the battery is calculated as $3502.37 \mathrm{~mm}^{3}$ with $-0.26 \%$ error. With this validation, volume calculation by the image processing method gives very accurate results.

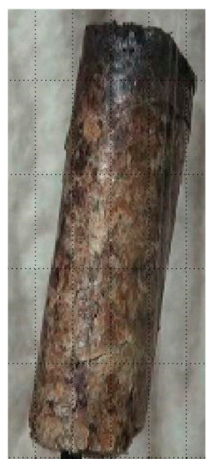

(a)

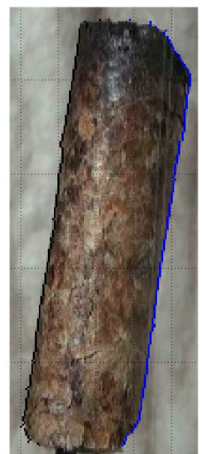

(b)

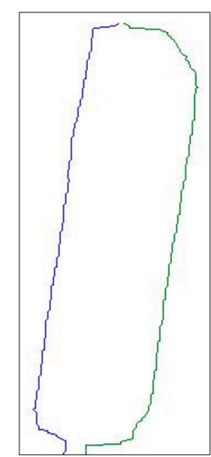

(c)

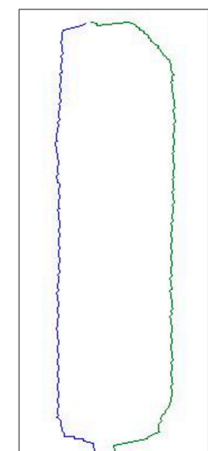

(d)

Figure 7. Wood pellet image data and image process results (finding border of wood pellet). (a) Raw image file; (b) Image file with border line; (c) Border line; (d) Border line with rotation.
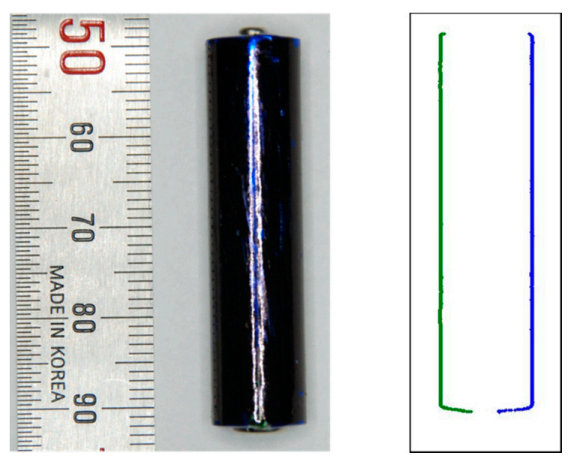

Figure 8. Picture of "AAA" type battery and image process result.

\section{Experimental Results and Discussion}

\subsection{Test Facility}

We performed an experimental study to measure the volume and mass of a burning wood pellet and captured images of a burning wood pellet. First, a wood pellet combustion facility was manufactured. A schematic diagram of the combustion facility is shown in Figure 9. To measure the air flow rate, a turbine type gas flow meter was used.

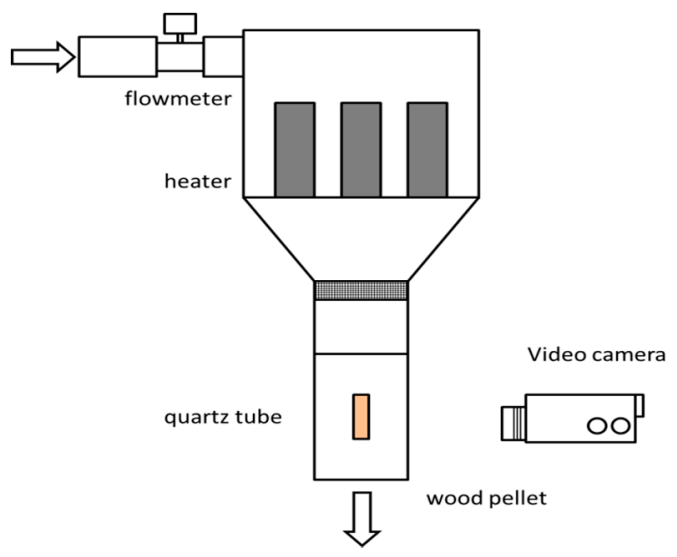

Figure 9. Schematic diagram of experimental facility. 
The combustion apparatus has $3 \times 1.6 \mathrm{~kW}$ electric heaters with a fan and $2 \times 0.5 \mathrm{~kW}$ bar type heaters to raise the air temperature. Air with a high temperature of up to $600{ }^{\circ} \mathrm{C}$ passes through a honeycomb mesh and a transparent quartz tube where a tested wood pellet is placed vertically. Air temperature is measured by a K-type thermocouple. Images of the burning wood pellet are captured by a digital video camera (SONY HDR-CX550). In the image processing program, a video image file is converted into snapshot image files at $0.5 \mathrm{~s}$ intervals. The combustion chamber maintained a steady state throughout the test.

\subsection{Volume Measurement Results}

Table 1 shows proximate and ultimate analysis results of the tested wood pellet and Table 2 represents wood pellet size and test condition.

Table 1. Proximate and ultimate analysis results of tested wood pellet. (Korea Institute of Energy Research, Testing and Certification Center).

\begin{tabular}{ccc}
\hline Higher Heating Value at Dry $\mathbf{( M J} / \mathbf{k g}, \mathbf{k c a l} / \mathbf{k g})$ & $\mathbf{1 8 . 6}(\mathbf{4 5 5 0 )}$ \\
\hline & Moisture & 8.73 \\
Proximate analysis (weight $\%$, as received) & Volatile & 73.98 \\
& Ash & 0.40 \\
& Fixed carbon & 16.89 \\
\hline Ultimate analysis (weight $\%$, as dried and ash free) & Carbon & 49.90 \\
& Hydrogen & 6.21 \\
& Nitrogen & 0.38 \\
& Oxygen & 43.10 \\
& Sulfur & 0.01 \\
\hline
\end{tabular}

Table 2. Wood pellet size and air conditions.

\begin{tabular}{cccc}
\hline \multicolumn{2}{c}{ Wood Pellet } & \multicolumn{2}{c}{ Air Condition } \\
\hline mass $(\mathrm{g})$ & 0.8065 & $Q_{\text {air }}\left(\mathrm{Nm}^{3} / \mathrm{h}\right)$ & 11.2 \\
length $(\mathrm{mm})$ & 22.01 & $T_{0}\left({ }^{\circ} \mathrm{C}\right)$ & 20.1 \\
diameter $(\mathrm{mm})$ & 6.12 & $T_{\mathrm{h}}\left({ }^{\circ} \mathrm{C}\right)$ & 544.7 \\
\hline
\end{tabular}

In the combustion of the wood pellet, there are three modes: (1) a gasification mode, (2) a flame burning mode, and (3) a charcoal burning mode. When the wood pellet is inserted into the combustion chamber with $T_{\mathrm{h}}>400^{\circ} \mathrm{C}$, there is no significant change in its appearance except that the surface color of the pellet becomes dark. This period is the gasification mode. The wood pellet is heated during this period and suddenly a flame starts from the head of the pellet; this flame then expands to the entire wood pellet due to vigorous volatilization. This is the flame burning mode. If there is no flame the charcoal burning mode starts. From the insertion of the wood pellet to the end of the charcoal mode, a video sequence of the burning wood pellet is captured and the volume of the wood pellet is subsequently calculated with an image process. To confirm the image processing result, we also measured nine wood pellet volumes at each mode every $20 \mathrm{~s}$ (four wood pellets in gasification mode, one wood pellet in burning mode, and four wood pellets in charcoal mode). Table 3 shows images of wood pellet at each combustion mode and converted images.

Figure 10 shows the volume change results of a burning wood pellet by an off-line and an on-line measurement. The on-line measurement refers to the measurement by the image processing method, which can measure the volume of the burning wood pellet continuously.

The off-line measurement entails measuring the volume of the burning wood pellet by intermittent sampling and it is repeated twice for each off-line measurement. For example, to check the volume of the burning wood pellet at $80 \mathrm{~s}$, we prepare a new wood pellet and put it in the combustion chamber for $80 \mathrm{~s}$, and then remove the burning chamber from the combustion chamber. After cooling the 
burning wood pellet, we measure the mass of the pellet on a scale and take pictures to measure the volume of the pellet. In the off-line measurement, there is a possibility of error in mass and volume measurements due to mass reduction during cooling of the burning wood pellet and measurement period. There is a difference in the volume between on-line and off-line measurements, especially in charcoal mode; the reason for this is shown in Figure 10.

Table 3. Images of wood pellet at each combustion mode.

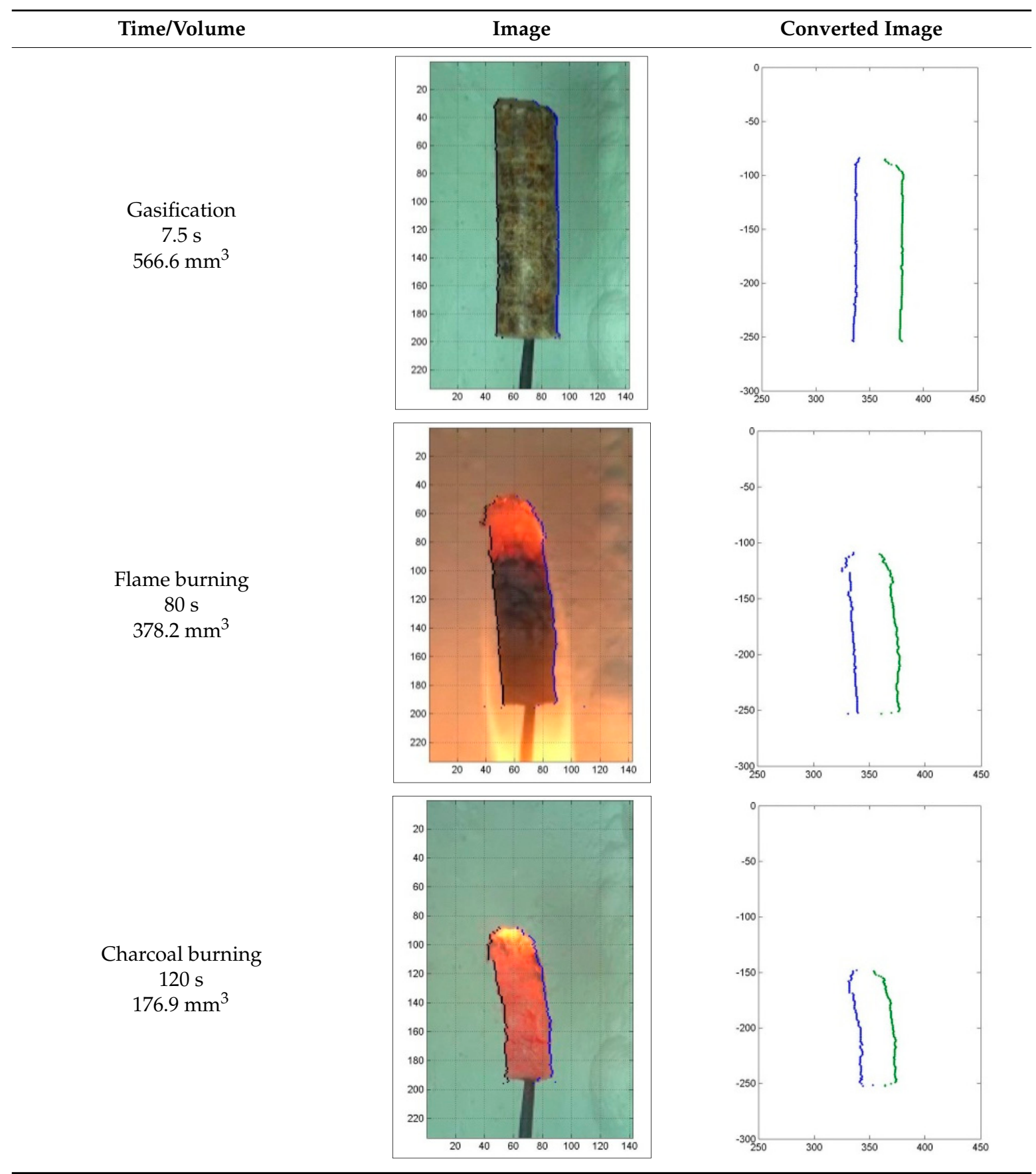


Table 3. Cont.

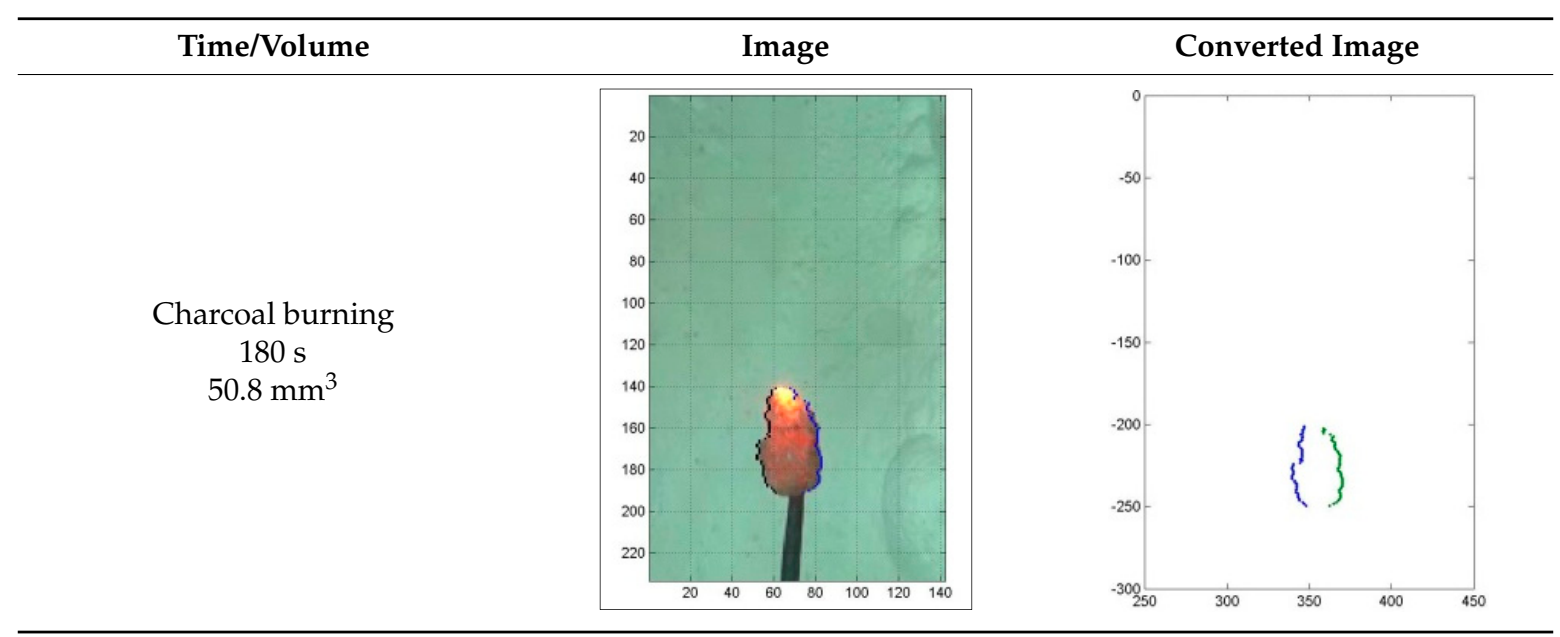

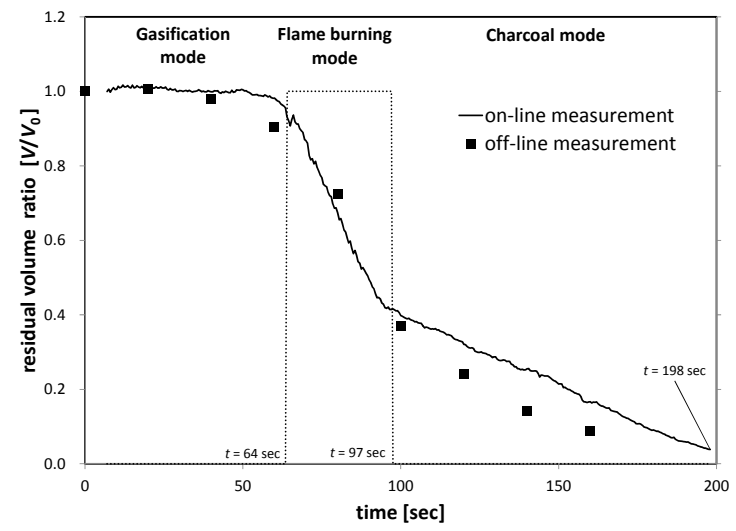

Figure 10. Comparison of volume measurement between off-line and on-line measurement.

At the beginning of the gasification mode, there is a volume increase caused by evaporation of water and pyrolysis inside the wood pellet (Figure 10). In the gasification mode, the volume change is very low. However, in the flame burning mode, an abrupt volume change occurs due to high energy emission by flame burning. The charcoal burning mode takes a long time: up to $51.6 \%$ of the total burn time. With this volume measurement method, we can easily and continuously measure volume change of the burning wood pellet, without any disturbance of combustion condition, from gasification mode to the end of combustion. At the end of combustion, the wood pellet's volume was $5 \%$ of the original pellet. We compare standardized char conversion time (char conversion time divided by density of the wood pellet) to a previous study by Biswas et al. [18]. Char conversion time is defined as the period starting at the moment when the flame around the pellet disappeared until the moment that the glowing of the char stopped [18]. Biswas et al. concluded that standardized char conversion times of the wood pellet with apparent density up to $1200 \mathrm{~kg} / \mathrm{m}^{3}$ remain constant about $80-100 \mathrm{~cm}^{3} \cdot \mathrm{s} / \mathrm{g}$. In the present study, standardized char conversion time is $82.3 \mathrm{~cm}^{3} \cdot \mathrm{s} / \mathrm{g}$, as shown in Figure 11.

During off-line measurement, we measure volume and mass of the wood pellet at each sampling. From the measurement, we can find the density of the wood pellet at each sampling, i.e., density is mass divided by volume. Figure 12 shows wood pellet density measurement results and data fitting for calculation of the wood pellet. From the beginning of gasification mode to the end of flame burning mode, the density of wood pellet decreases as a quadratic function. On the contrary, density of the wood pellet at charcoal mode is almost constant and density average value is $307.5 \mathrm{~kg} / \mathrm{m}^{3}$. So we assume density as a quadratic function that passes through $\rho_{\text {wood pellet }}\left(1213 \mathrm{~kg} / \mathrm{m}^{3}\right)$ at $t=0 \mathrm{~s}$ and $\rho_{\text {charcoal }}\left(307.5 \mathrm{~kg} / \mathrm{m}^{3}\right)$ at the end of flame burning mode $(t=94 \mathrm{~s})$ as the following equation: 


$$
\rho=\mathrm{a} t^{2}+\rho_{\text {charcoal }}=0.09627 t^{2}+1213
$$

Mass measurement by off-line (black square point) and calculation results of the mass of the burning wood pellet based on volume measurement (line) are shown in Figure 13. The mass of the burning wood pellet is calculated by multiplication volume measured by on-line method and density fitted, as shown in Figure 12. The dash line represents the previous research result of residual mass ratio by Biswas et al. [18]. Test conditions between the present study and previous studies differ from each other, especially air temperature. Air temperature in the present study is about $545^{\circ} \mathrm{C}$ and $80{ }^{\circ} \mathrm{C}$ in a previous study. With two data sets (the result from the present study and the result by Biswas et al.), we can confirm the end time of flame burning. The end time of flame burning of the present study is $97 \mathrm{~s}$, and that of Biswas et al.'s is $50 \mathrm{~s}$. So we add $47 \mathrm{~s}$ with time data of Biswas et al. In spite of different test conditions, charcoal mode results are in alignment. However, air temperature of Biswa et al.'s study is higher than that of the present study, so duration of gasification mode of Biswas et al. is less than $5 \mathrm{~s}$. In gasification mode of the present study, residual mass ratio is dropped from 1.0 to 0.63 and in flame burning mode, residual mass ratio is dropped from 0.63 to 0.10 . Compared to residual volume ratio result in Figure 10, gasification modes differ from each other. Before flame burning, volume change is less than $7 \%$ p (from $100 \%$ to $93 \%$ ). However, mass reduction is about $37 \%$ $\mathrm{p}$ (from $100 \%$ to $63 \%$ ). Figure 14 shows the volume and mass reduction rate of the burning wood pellet with respect to each burning mode. Volume and mass reduction rates during charcoal burning mode drastically differ from each other.

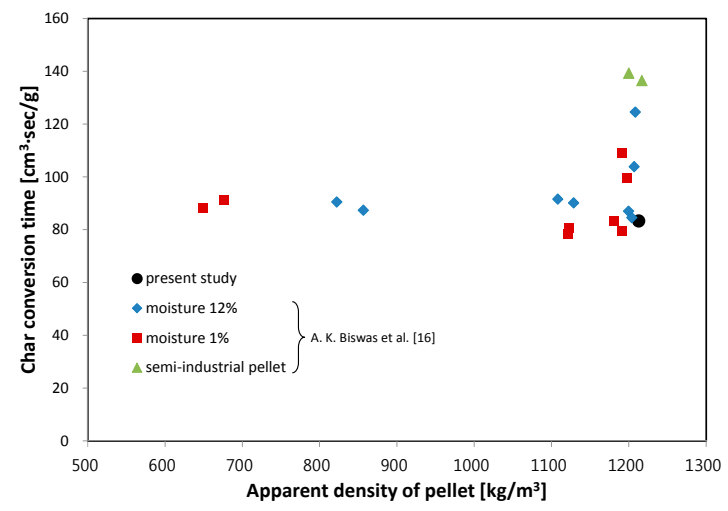

Figure 11. Comparison of standardized char conversion time $\left(\mathrm{cm}^{3} \cdot \mathrm{s} / \mathrm{g}\right)$ between result of present study and previous research data by Biswas et al. [18].

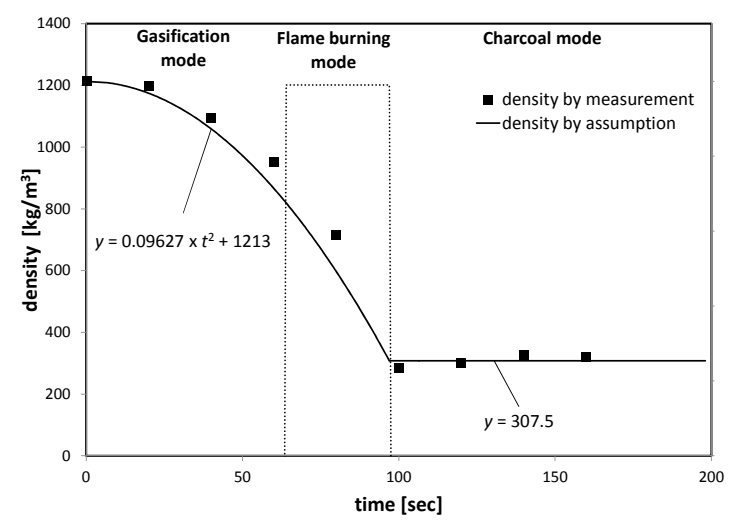

Figure 12. Wood pellet density measurement results and data fitting for mass calculation of wood pellet at each time. 


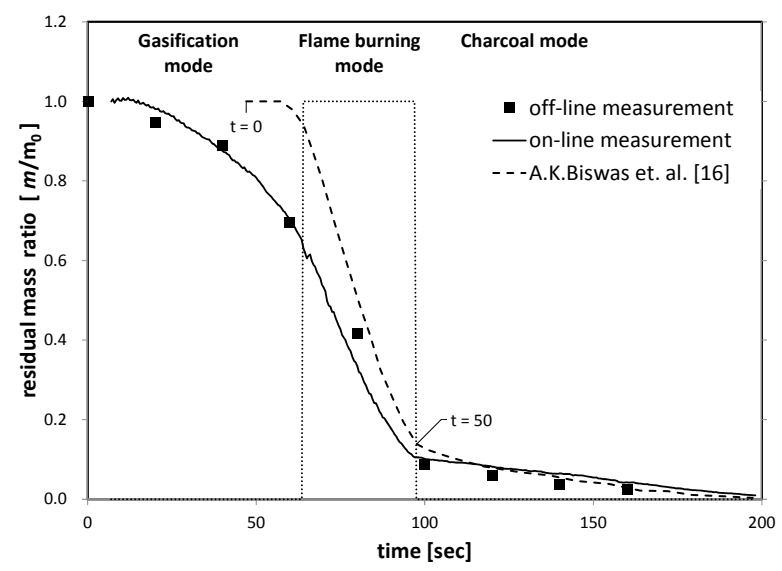

Figure 13. Residual mass ratio by off-line and on-line measurement with respect to elapsed time and previous research data by Biswas [18].

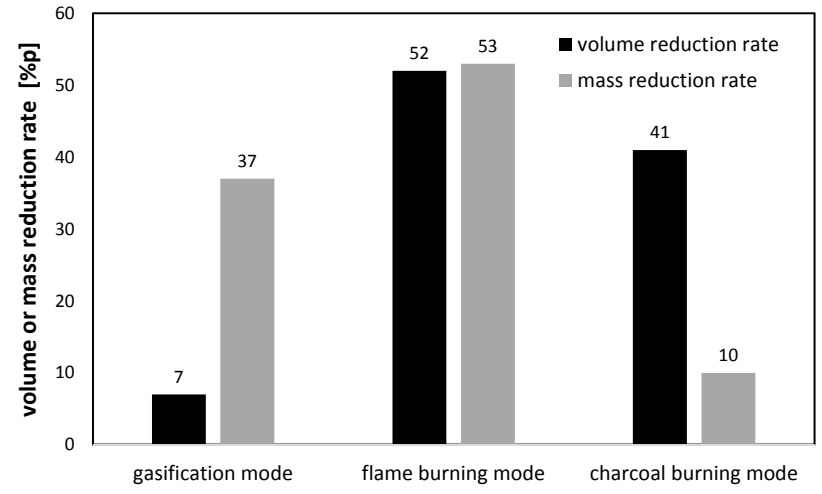

Figure 14. Comparison between volume and mass reduction rate of burning wood pellet.

At the end stage of wood pellet burning, $41 \%$ of the volume of the original wood pellet remains, however, only $10 \%$ of the mass remains. In this study, charcoal burning mode takes $101 \mathrm{~s}$, which is $51 \%$ of the whole combustion period. Conversely, flame burning mode takes $33 \mathrm{~s}$, which is $17 \%$ of the whole combustion period. Given this result, it is evident that the wood pellet combustor promotes a relatively long period of charcoal burning mode with a bulky volume of charcoal.

\section{Conclusions}

In this research, we developed a volume measurement method for a burning wood pellet. With a video camera, images of a burning wood pellet are continuously captured and then converted to image files to calculate the volume of the wood pellet at each time point. Each of the off-line volume measurements with division into eight parts of complete burning were conducted twice and compared with on-line measurement data. Wood pellets used in the combustion test were 1st grade in Korea. Conclusions and findings of the research are as follows:

1. Compared to the volume measurement taken by a ruler (vernier caliper), the error of the developed volume measurement method is $-0.26 \%$.

2. With the image processing method, we can measure the instantaneous volume of the burning wood pellet with high precision without disturbance of the combustion environment.

3. Three combustion modes of the wood pellet can easily be distinguished by the image processing program. Gasification mode takes $32.3 \%$ of the total burn time, flame burning mode takes $16.7 \%$, and charcoal burning mode takes $51.0 \%$ under the tested conditions. 
4. From gasification mode to end of flame burning mode, density of burning wood pellet decreases as a quadratic function. In charcoal mode, the density of the burning wood pellet is constant at about $307.5 \mathrm{~kg} / \mathrm{m}^{3}$.

5. In gasification mode in this research, mass reduction of the wood pellet is $37 \%$ and volume reduction of the wood pellet is $7 \%$. On the contrary, in charcoal burning mode, mass reduction of the wood pellet is $10 \%$ and volume reduction of the wood pellet is $41 \%$. Relatively large volume reduction, small mass reduction and long burning duration in charcoal burning mode should be considered in designing a wood pellet combustor.

Acknowledgments: This work was conducted under the framework of Research and Development Program of the Korea Institute of Energy Research (KIER, Korea) (B7-2414-02).

Author Contributions: Sae Byul Kang and Jong Jin Kim conceived and designed the experiments. Bong Suk Sim conducted experiment on combustion characteristics and measurement of size of combusted pellets. Calculation of volume of a wood pellet was done by Sae Byul Kang.

Conflicts of Interest: The authors declare no conflict of interest.

\section{References}

1. Korea Energy Agency. Overview of New and Renewable Energy in Korea 2015. 2016. Available online: http:// www.knrec.or.kr $/$ knrec/14/KNREC140310.asp?idx=80\&page=1\&num=24\&Search=\&SearchString=\# (accessed on 16 April 2017).

2. Forest Biomass Energy Association (Korea). 2016. Available online: http://www.biomassenergy.kr (accessed on 16 April 2017).

3. European Biomass Association (AEBIOM). AEBIOM Statistical Report 2016; European Biomass Association: Brussel, Belgium, 2016.

4. European Committee for Standardization. EN-303-5:2012 Heating Boilers-Part 5: Heating Boilers for Solid Fuels, Hand and Automatically Stocked, Nominal Heat Output of up to $500 \mathrm{~kW}$-Terminology, Requirements, Testing and Marking; European Committee for Standardization: Brussel, Belgium, 2012.

5. Fiedler, F. The state of the art of small-scale pellet-based heating systems and relevant regulations in Sweden, Austria and Germany. Renew. Sustain. Energy Rev. 2004, 8, 201-221. [CrossRef]

6. Finney, K.N.; Sharifi, V.N.; Swithenbank, J. Combustion of spent mushroom compost and coal tailing pellets in a fluidized bed. Renew. Energy 2009, 34, 860-868. [CrossRef]

7. Niedziołka, I.; Szpryngiel, M.; Kachel-Jakubowska, M.; Kraszkiewicz, A.; Zawislak, K.; Sobczak, P.; Nadulski, R. Assessment of the energetic and mechanical properties of pellets produced from agricultural biomass. Renew. Energy 2015, 76, 312-317. [CrossRef]

8. Barbanera, M.; Lascaro, E.; Stanzione, V.; Esposito, A.; Altieri, R.; Bufacchi, M. Characterization of pellets from mixing olive pomace and olive tree pruning. Renew. Energy 2016, 88, 185-191. [CrossRef]

9. Liu, Z.; Liu, X.; Fei, B.; Jiang, Z.; Cai, Z.; Yua, Y. The properties of pellets from mixing bamboo and rice straw. Renew. Energy 2013, 55, 1-5. [CrossRef]

10. Liu, Z.; Mi, B.; Jiang, Z.; Fei, B.; Cai, Z.; Liu, X. Improved bulk density of bamboo pellets as biomass for energy production. Renew. Energy 2016, 86, 1-7. [CrossRef]

11. Obidzinski, S.; Piekut, J.; Dec, D. The influence of potato pulp content on the properties of pellets from buckwheat hulls. Renew. Energy 2016, 87, 289-297. [CrossRef]

12. Thunman, H.; Leckner, B.; Niklasson, F.; Johnsson, F. Combustion of wood particles-A particle model for Eulerian calculations. Combust. Flame 2002, 129, 30-46. [CrossRef]

13. Park, W.C.; Atreya, A.; Baum, H.R. Experimental and theoretical investigation of heat and mass transfer processes during wood pyrolysis. Combust. Flame 2010, 157, 481-494. [CrossRef]

14. Hshieh, F.Y.; Richards, G.N. The effect of preheating of wood on ignition temperature of wood char. Combust. Flame 1989, 80, 395-398. [CrossRef]

15. Ward, S.M.; Braslaw, J. Experimental weight loss kinetics of wood pyrolysis under vacuum. Combust. Flame 1985, 61, 261-269. [CrossRef]

16. Lautenberger, C.; Fernandez-Pello, C. A model for the oxidative pyrolysis of wood. Combust. Flame 2009, 156, 1503-1513. [CrossRef] 
17. Kung, H.C.; Kalelkar, A.S. On the heat of reaction in wood pyrolysis. Combust. Flame 1973, 20, 91-103. [CrossRef]

18. Biswas, A.K.; Rudolfsson, M.; Broström, M.; Umeki, K. Effect of pelletizing conditions on combustion behaviour of single wood pellet. Appl. Energy 2014, 119, 79-84. [CrossRef]

19. Fagerström, J.; Steinvall, E.; Boström, D.; Boman, C. Alkali transformation during single pellet combustion of soft wood and wheat straw. Fuel Process. Technol. 2016, 143, 204-212. [CrossRef]

20. Ström, H.; Thunman, H. CFD simulations of biofuel bed conversion: A submodel for the drying and devolatilization of thermally thick wood particles. Combust. Flame 2013, 160, 417-431. [CrossRef]

21. Sengupta, A.; Roy, S.; Sengupta, S. Development of a low cost yarn parameterisation unit by image processing. Measurement 2015, 59, 96-109. [CrossRef]

22. Taghavifar, H.; Mardani, A. Potential of functional image processing technique for the measurements of contact area and contact pressure of a radial ply tire in a soil bin testing facility. Measurement 2013, 46, 4038-4044. [CrossRef]

23. Arce, M.E.; Saavedra, Á.; Míguez, J.L.; Granada, E.; Cacabelos, A. Biomass fuel and combustion conditions selection in a fixed bed combustor. Energies 2013, 6, 5973-5989. [CrossRef]

24. Moradian, F.; Pettersson, A.; Svärd, S.H.; Richards, T. Co-combustion of animal waste in a commercial waste-to-energy BFB boiler. Energies 2013, 6, 6170-6187. [CrossRef]

25. Chun, Y.N.; Ji, D.W.; Yoshikawa, K. Pyrolysis and gasification characterization of sewage sludge for high quality gas and char production. J. Mech. Sci. Technol. 2013, 27, 263-272. [CrossRef]

26. Gómez, M.A.; Comesaña, R.; Feijoo, M.A.Á.; Eguía, P. Simulation of the effect of water temperature on domestic biomass boiler performance. Energies 2012, 5, 1044-1061. [CrossRef]

(C) 2017 by the authors. Licensee MDPI, Basel, Switzerland. This article is an open access article distributed under the terms and conditions of the Creative Commons Attribution (CC BY) license (http:/ / creativecommons.org/licenses/by/4.0/). 